Sandberg, S. (2013). Lean in: Women, work, and the will to lead. New York, NY: Random House.

Sherif, M., Harvey, O. J., White, B. J., Hood, W. R., \& Sherif, C. W. (1961) Intergroup conflict and cooperation: The robbers cave experiment. Norman, OK: University of Oklahoma Book Exchange.

Streets, V. N. (2016). Reconceptualizing women's STEM experiences: Building a theory of positive marginality (Doctoral dissertation). Retrieved from ProQuest Dissertations \& Theses Global. (Accession No. 10248358).

Taylor, J. C., \& Stern, G. M. (2009). The trouble with HR: An insider's guide to finding and keeping the best people. New York, NY: AMACOM.

Thorpe-Moscon, J. (2017). Turn perception into reality. Retrieved from http://www.catalyst.org/ knowledge/turn-perception-reality- 0 .

\title{
Bridging Individual and Social-Structural Perspectives
}

Kristi Lavigne and Rachel Rauvola

Saint Louis University

A paradigm shift toward a social-structural perspective may provide a better understanding of the gender inequity in STEM fields than its predecessor, but this perspective falls prey to the focal article authors' (Miner et al., 2018) own criticisms: It offers an incomplete account of the phenomenon of interest. We argue that a multilevel systems perspective is the most appropriate approach when trying to understand any issue, especially an issue as dense as gender inequity in STEM. A deliberate effort to understand this phenomenon dynamically across levels and time can expand the scope of industrial and organizational (I-O) psychologists' influence and can better protect us against interventions that result in unintended, adverse outcomes. Below, we discuss the importance of looking across multiple levels simultaneously to understand the temporal and interactional nature of individual and social-structural constructs. Without this depth of understanding, a disruption of the current structure may lead to an unstable, or unanticipated, new structure.

One assumed advantage of a social-structural perspective is its ability to better explain gender inequity in STEM. Unfortunately, few studies consider both individual and social-structural causal factors simultaneously and comparatively. There is reason to believe that an individual perspective contributes meaningful incremental variance in explaining gender inequity. For example, some research suggests that stereotypes more accurately reflect the target when the scores from the stereotype holders are aggregated to the

Kristi Lavigne, Saint Louis University; Rachel Rauvola, Saint Louis University.

Correspondence concerning this article should be addressed to Kristi Lavigne, Saint Louis University, Saint Louis, MO. E-mail: kristi.lavigne@slu.edu 
group level (Kite, Deaux, Haines, Denmark, \& Paludi, 2008). Another indication comes from the abundance of stereotype research focusing on individual differences in stereotypes held, particularly stereotype strength. Whereas gender stereotype structure tends to be relatively consistent across cultures (Sczesny, Bosak, Neff, \& Schyns, 2004), the degree to which this structure influences vocational outcomes depends upon individual-level variance in stereotype strength (Smyth \& Nosek, 2015).

Another advantage of the social-structural perspective mentioned by the focal article is the step away from explaining group differences in terms of individual attitudes, cognitions, and behaviors. Although the social-structural perspective views the cause of group behavior as stemming from a grouplevel structure (e.g., gender ratios, gender norms), there are multiple avenues for individual-level psychological mechanisms (e.g., self-selection into environment, occupational self-efficacy beliefs) to exert their influence beyond simple additive (i.e., "either-or," "better than") contributions to gender inequity. From a multilevel lens, this occurs both through emergence and cross-level interactions. First, any social structure purported to cause gender inequity in STEM must emerge from individual-level interactionsmust be constructed through social interaction over time-before becoming a structure. Continued stability in these relationships is necessary for the preservation of the structural form and its causal influence (Elder-Vass, 2007). Without understanding how the social structure is created from the ground up (and can thus be manipulated), the social-structural perspective loses practical utility. To take another example, power dynamics, although structurally exerted (e.g., policy, executive decisions, and the messages they convey), also notably emerge and are enacted by individuals. A focus on both levels can be reasonably maintained from a multilevel perspective, which may help us to avoid the pitfalls of assigning too much agency (e.g., "victim blaming") or too little agency (e.g., structure reinforcement, perceived helplessness) with regard to gender outcomes in STEM. By considering both, the individual-level interventions can be leveraged to catalyze a new structure or to buffer the effects of the old structure while waiting for the new structure to emerge. Thus, although neglected in the focal article, there are cross-level considerations regarding the emergence of, and interaction between, social-structural factors that should include the individual as a focal unit.

The authors further contend that a social-structural approach provides a novel perspective for organizational interventions, some of which they present in their work. However, if gender inequity in STEM is due to socialstructural forces that send the message that one gender is more equipped to fulfill a certain role (e.g., vocational role, domestic role), then the organizational solutions offered by the authors (e.g., job redesign, flexible work 
characteristics) may not prove effective in reducing gender inequity. The socially constructed roles within society (e.g., childrearing, breadwinning) and work (e.g., speech pathologist, physicist) are attached to gender roles by the common attributes relevant to each role (Eagly \& Karau, 2002; Hogue \& Lord, 2007). Formally redesigning jobs in gender-neutral terms and creating flexible organizational policies may be advantageous to both male and female workers, and thus permit the change of the social structure beyond work; however, expulsion of the current prototypes and stereotypes needs to occur simultaneously in order to create social-structural change. I-O psychologists should adopt the goal of drowning out inaccuracies in group-level assumptions and changing outdated vocational prototypes to reflect skills needed. Otherwise, the benefits of this flexibility may make gendered roles such as childrearing easier for women to fulfill, while allowing men an opportunity to pursue additional roles more easily. Yet, the choices as to which roles to pursue will still be constrained by societal norms. Constructing organizational policies that send clear messages regarding the gender neutrality of roles (e.g., men and women both are equally capable of childrearing), such as providing men with paternity leave equal to that provided for women, might be a more effective top-down approach.

Social scientists interested in social-structural influences have been criticized for speaking vaguely about, and providing too few examples of, socialstructural factors (e.g., Porpora, 2007). For psychologists, this may partially be due to the overutilization of a strong individual lens when theorizing and investigating relationships in the past. With the application of a new perspective, whether a multilevel perspective encompassing socialstructural constructs or a social-structural perspective, the clear definition of higher-level social-structural constructs, recognition of theoretically related constructs, and discussions of the emergence and operationalization of these constructs are required. Increased collaboration with more macrolevel social scientists, and familiarity with their work, may facilitate progress here.

If we attempt to conduct macrolevel work on our own, however, we will miss out on the rich body of knowledge and experience that can be gained through cross-disciplinary dialogue. Moreover, we will likely fall prey to the same trap that already plagues our field: the myopia of single-level theory and inquiry. The social-structural perspective, although underlining the important need for macro-level considerations, unfortunately still relies upon one level for its theory (e.g., socially constructed gender roles and society-level gender ratios in STEM). Although we are in great need of looking "up" more often, we cannot forget to look down, around, and between as well. Only then can we have integrative theory and practice that is compatible across levels, objectives, and (perhaps one day) disciplines. 


\section{Conclusion}

The focal article calls for industrial-organizational psychologists to adopt a social-structural lens to address the issue of gender inequity in STEM, a reaction to industrial-organizational psychologists' general comfort with, and overreliance on, individual-level explanations. The present commentary goes a step further, emphasizing the need to adopt a multilevel perspective when considering causal factors of gender inequity rather than swinging from one single-level perspective to another. Doing so will allow us to more comprehensively and accurately account for the causal influences and identify the most appropriate leverage points to reduce gender inequity.

\section{References}

Eagly, A. H., \& Karau, S. J. (2002). Role congruity theory of prejudice toward female leaders. Psychological Review, 109, 573-598. doi:10.1037//0033-295X.109.3.573

Elder-Vass, D. (2007). For emergence: Refining Archer's account on social structure. Journal for the Theory of Social Behavior, 37, 25-44. doi:10.1111/j.14685914.2007.00325.x

Hogue, M., \& Lord, R. G. (2007). A multilevel, complexity theory approach to understanding gender bias in leadership. Leadership Quarterly, 18, 370-390. doi:10.1016/j.leaqua.2007.04.006

Kite, M. E., Deaux, K., Haines, E. L., Denmark, F. L., \& Paludi, M. A. (2008). Gender stereotypes. In F. L. Denmark \& M. Antoinette (Eds.), Psychology of women: A handbook of issues and theories (pp. 205-236). London, UK: Praeger.

Miner, K. N., Walker, J. M., Bergman, M. E., Jean, V. A., Carter-Sowell, A., January, S. C., \& Kaunas, C. (2018). From "her" problem to "our" problem: Using an individual lens versus a social-structural lens to understand gender inequity in STEM. Industrial and Organizational Psychology: Perspectives on Science and Practice, 11(2), 267-290.

Porpora, D. (2007). On Elder-Vass: Refining a refinement. Journal for the Theory of Social Behavior, 37, 195-200. doi:10.1111/j.1468-5914.2007.00332.x

Sczesny, S., Bosak, J., Neff, D., \& Schyns, B. (2004). Gender stereotypes and the attribution of leadership traits: A cross-cultural comparison. Sex Roles, 51, 631-645. doi:10.1007/s11199-004-0715-0

Smyth, F. L., \& Nosek, B. A. (2015). On the gender-science stereotypes held by scientists: Explicit accord with gender-ratios, implicit accord with scientific identity. Frontiers in Psychology, 6, 415. doi:10.3389/fpsyg.2015.00415 